14.4

\title{
Мандельштам-бриллюэновское рассеяние света в растворах бычьего сывороточного альбумина при различных концентрациях в окрестности тепловой денатурации
}

\author{
(C) А.В. Дмитриев, А.И. Федосеев, С.Г. Лушников
}

Физико-технический институт им. А.Ф. Иофффе РАН, 194021 Санкт-Петербург, Россия

e-mail: sergey.lushnikov@mail.ioffe.ru

Поступило в Редакцию 20 апреля 2020 г.

В окончательной редакции 20 апреля 2020 г.

Принято к публикации 20 апреля 2020 г.

С помощью мандельштам-бриллюэновского рассеяния света проведены исследования фазовых превращений бычьего сывороточного альбумина (БСА) в области температур от 300 до $380 \mathrm{~K}$ в растворах с концентрациями 50 и $5 \mathrm{mg} / \mathrm{ml}$. В анализе результатов в качестве реперной использовалась последовательность фазовых превращений в концентрированном $(100 \mathrm{mg} / \mathrm{ml})$ растворе БСА. Показано, что последовательность фазовых превращений БСА модифицируется при уменьшении концентрации. Так, например, в области денатурации исчезает область с фибриллоподобными агрегатами белка, и меняются свойства гелеобразной высокотемпературной фазы.

Ключевые слова: мандельштам-брюллюэновское рассеяние света, бычий сывороточный альбумин, фазовые превращения, агрегаты, гелеподобная фаза.

DOI: 10.21883/JTF.2020.10.49789.140-20

\section{Введение}

Динамика биополимеров является одной из междисциплинарных областей знаний, лежащей на стыке физики конденсированных сред, молекулярной биологии, биохимии и других дисциплин. Более того она лежит в области, находящейся в фокусе внимания фундаментальной и практической медицины, поскольку уже хорошо известно, что изменения в структуре и динамике биополимеров могут приводить к изменениям их активности и биологических функций. Так, например, нарушения в структуре белка могут приводить к возникновению ненативных белок-белок взаимодействий, что в свою очередь приводит к процессам агрегации. Сегодня считается, что агрегация белков в организме является причиной многих нейроденегеративных заболеваний. Примером таких агрегатов могут служить фибриллы, вытянутые структуры, образующиеся за счет образования $\beta$-слоев между белками. Белки, участвующие в образовании фибриллоподобных структур, больше не могут выполнять свои биологические функции [1]. Таким образом, механизмы, ответственные за образования агрегатов, гелеподобных структур в последнее десятилетие являются предметом активных исследований с помощью различных физических методов. Одним из таких методов является мандельштам-бриллюэновское рассеяние (МБР) света. Это обусловлено тем, что динамика биополимеров в диапазоне частот от 1 до $1000 \mathrm{GHz}$ обычно отражает локальные конформационные изменения, т.е. прыжки атомов от одной конфигурации к другой, и коллективные возбуждения. Динамика биополимеров в этом диапазоне частот имеет много общего с динамикой стекол, переохлажденных жидкостей и других конденсированных сред. Например, в колебательном спектре белков обнаружены бозонный пик, быстрые ангармонические движения, подобные быстрой пикосекундной релаксации в стеклах, и др. [2,3]. МБР света дает возможность изучать колебательный спектр биополимеров в указанном диапазоне частот с высокой точностью и с минимальными воздействиями на изучаемую систему. Эффективность МБР света в исследовании динамики биополимеров была показана при изучении перехода ДНК из $A$ в $B$ форму, плавлении ДНК [4 и ссылки в ней], тепловой денатурации белков $[5,6]$ и динамики коротких пептидов [7]. В одном из недавних исследований белков с помощью МБР света была восстановлена последовательность фазовых превращений бычьего сывороточного альбумина (БСА) в $0.1 \mathrm{M}$ натрий-фосфатном буфере с концентрацией $100 \mathrm{mg} / \mathrm{ml}$ при нагревании (рис. 1) [5]. Эта последовательность хорошо согласуется с известными литературными данными и состоит из нескольких температурных областей. До $330 \mathrm{~K}$ белок в растворе находится в нативном состоянии, т.е. $330 \mathrm{~K}$ является верхней температурной границей обратимых структурных изменений, которые можно в целом описать как движения доменов белка относительно друг друга. При дальнейшем увеличении температуры все последующие структурные изменения являются необратимыми и сопровождаются процессами агрегации. Из рис. 1 видно, что область денатурации включает в себя три различных состояния. Границы области денатурации определены по результатам экспериментов по неупругому рассеянию 


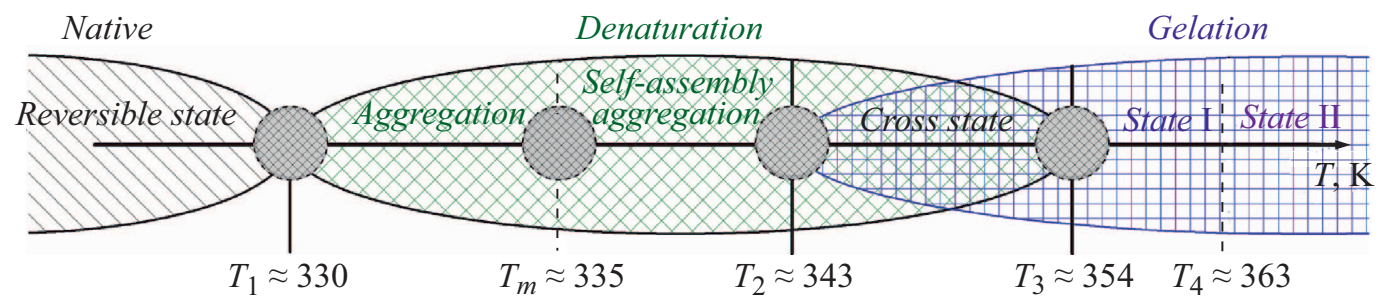

Рис. 1. Последовательность фазовых превращений в растворе БСА с концентрацией $100 \mathrm{mg} / \mathrm{ml}$ в $0.1 \mathrm{M}$ натрий-фосфатном буфере [5].

нейтронов [8]. Белок БСА - трехдоменный белок, причем раскрытие доменов происходит неодновременно при тепловой денатурации [9]. Так, при достижении температуры плавления $T_{m}=335 \mathrm{~K}$ начинается процесс раскрытия II домена, который сопровождается увеличением количества $\beta$-слоев, что приводит к образованию в растворе самосогласованных агрегатов. Фаза с ориентированными и крупными (размер которых сопоставим с длинной волны) фибриллоподобными агрегатами в диапазоне температур $343<T<347 \mathrm{~K}$ переходит в гелеподобную фазу, при этом в окрестности температуры $T_{2}=343 \mathrm{~K}$ начинается процесс раскрытия I домена. При температуре выше $T_{2}$ фибриллоподобные агрегаты переориентируются и образуют полимерную сетку, которая в конечном итоге превращается в гель в окрестности $T_{4}=363 \mathrm{~K}$ (рис. 1). Гелеподобная фаза в БСА состоит из двух различных состояний, отличающихся фрактальной размерностью [10]. В работе было показано, что трансформация вторичной и третичной структуры белка, его агрегация и гелеобразование в растворе БСА проявляются в спектрах МБР света в виде аномалий скорости и затухания гиперзвука, интенсивности рэлеевской компоненты и мандельштам-бриллюэновского дублета.

Анализ литературных данных, результатов наших измерений показал, что последовательность фазовых превращений белков в растворе определяется внешними условиями, такими, как рН буфера, давление, концентрация белка и т.д. [11]. Это мотивировало нас исследовать влияние концентрации БСА на низкочастотную динамику белка и последовательность фазовых превращений в окрестности денатурации с помощью мандельштамбриллюэновского рассеяния света. В ходе настоящей работы мы опирались на последовательность фазовых превращений концентрированного раствора $(100 \mathrm{mg} / \mathrm{ml})$ БСА, сравнивая с ней полученные результаты.

\section{1. Материалы и методы}

В качестве объекта исследований выступал раствор белка БСА (Sigma) с молекулярной массой $69 \mathrm{kDa}$. В качестве растворителей использовался $0.1 \mathrm{M}$ натрийфосфатный буфер с $\mathrm{pH}=7.45$. После приготовления белковые растворы были подвергнуты центрифугированию. С целью исключения крупных нерастворенных фрагментов супернатант был отфильтрован. Концентрация белка в буфере составляла 50 и $5 \mathrm{mg} / \mathrm{ml}$. Полученные результаты по МБР света в белковых растворах сравнивались с экспериментальными результатами с концентрацией белка в растворе $100 \mathrm{mg} / \mathrm{ml}$, приготовленному по аналогичному протоколу [5].

В качестве источника света в экспериментах по МБР света использовался аргоновый лазер с длинной волны $488 \mathrm{~nm}$ и мощностью $100 \mathrm{~mW}$. Луч лазера проходил через оптическую схему и фокусировался на образце. Эксперименты проводились в 180-градусной геометрии. Рассеянный свет анализировался с помощью трехпроходного пьезосканируемого интерферометра ФабриПеро и регистрировался с помощью системы счета фотонов. Для стабилизации и контроля интерферометра использовалась система DAS-1 фирмы Burleigh. Расстояние между зеркалами составляло $5.77 \mathrm{~mm}$, что соответствовало свободному спектральному интервалу $26 \mathrm{GHz}$. Время накопления одного спектра составляло $300 \mathrm{~s}$. Закрытая кварцевая кювета с раствором помещалась в самодельную печь с автоматической системой контроля и стабилизацией температуры с погрешностью менее $0.5 \mathrm{~K}$. Исследуемая область температур составляла $293<T<370$ К. МБР света в жидкостях определяется адиабатическими флуктуациями плотности и энтропии. Флуктуации плотности отвечают за появление в спектре компонент дублета МБР, а флуктуации энтропии - компоненты рэлеевского рассеяния. Флуктуации плотности в жидкости - это тепловые звуковые волны с частотой $\Delta v=V \mathbf{q} / 2 \pi$, где $V-$ скорость звука и $\mathbf{q}-$ волновой вектор. Они соответствуют дублету МБР с частотой $v_{0} \pm \Delta v \quad$ (где $v_{0}$ - частота возбуждающей линии) в спектре рассеянного света. Для интерпретации спектра рассеянного света для вязких жидкостей, в которых существует затухание звука, использовалось феноменологическое уравнение гидродинамики для средних значений - уравнение Стокса. Можно показать, что смещение компонент МБР $\Delta v$, отнесенное к частоте возбуждающего света $v_{0}$, пропорционально скорости упругих волн

$$
\pm \frac{\Delta v}{v_{0}}=2 n \frac{V}{c} \sin \frac{\theta}{2}
$$

где $n-$ коэффициент преломления и $\theta-$ угол между падающим и рассеянным лучами [12]. Полуширина на полувысоте компонент МБР дублета $(\delta \omega)$ связана с 


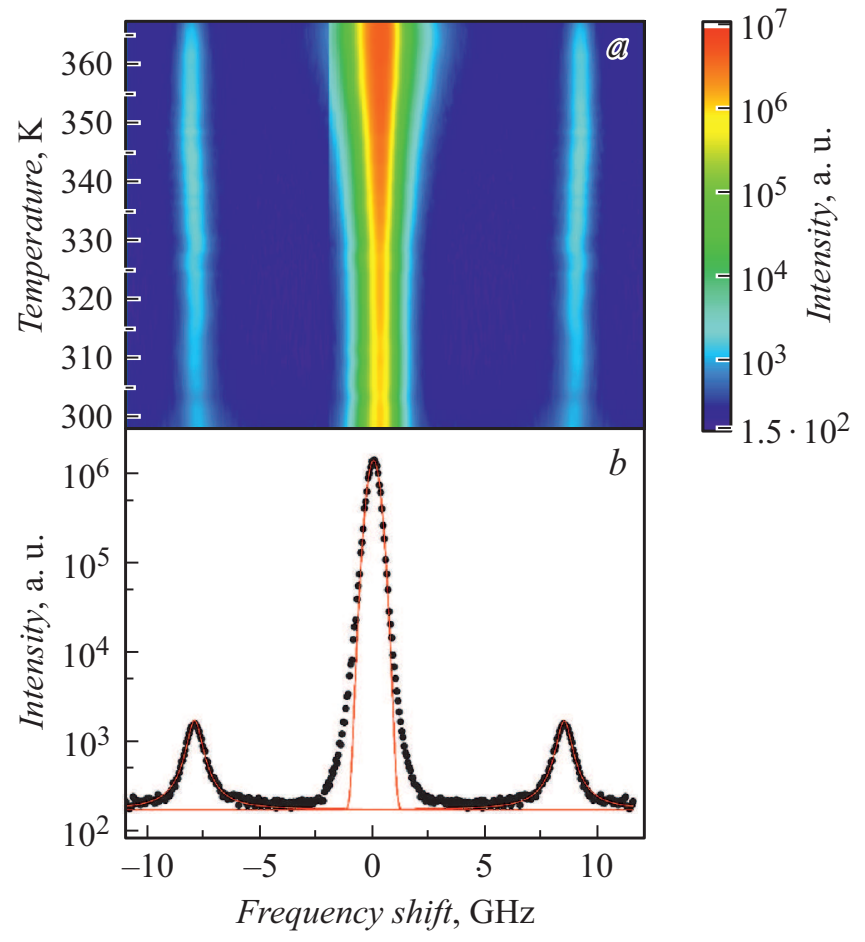

Рис. 2. Панель экспериментальных спектров рэлеевского и мандельштам-бриллюэновского рассеяния света при изменении температуры для раствора БСА с концентрацией $5 \mathrm{mg} / \mathrm{ml}$. Внизу показан пример обработки экспериментального спектра раствора БСА с концентрацией $5 \mathrm{mg} / \mathrm{ml}$ при $T=320 \mathrm{~K}$. Черные точки - экспериментальный результат, сплошная линия результаты обработки спектров с помощью предложенной в тексте модели.

затуханием упругой волны $(\alpha)$ и параметрами гидродинамической теории выражением

$$
\delta \omega=2 \alpha V=\mathbf{q}^{2}(4 \eta / 3+\xi) /(2 \rho)
$$

где $\eta$ и $\xi-$ коэффициенты сдвиговой и объемной вязкости соответственно и $\rho-$ плотность.

Пример экспериментального спектра рассеяния света с обработкой для белкового раствора с концентрацией $5 \mathrm{mg} / \mathrm{ml}$ показан на рис. 2, $b$. Экспериментальный спектр состоит из центральной компоненты на нулевой частоте (рэлеевское рассеяние), описываемое функцией Гаусса, и мандельштам-бриллюэновского дублета, форма линии каждой компоненты описывалась функцией Лоренца [5]. На рис. 2, а показана панель спектров с разверткой по температуре (по шкале $Y$ ). Цветом представлена интенсивность рассеянного света. Из рис. $2, a$ видно, что интенсивность и полуширина компоненты рэлеевского рассеяния света увеличивается с ростом температуры, в то время как для компоненты МБР дублета сдвиг частоты и интенсивность меняются при нагревании, а полуширина практически не зависит от температуры.

\section{2. Результаты и обсуждение}

\section{1. Температурное поведение относительного изменения сдвига частоты в растворах БСА различной концентрации}

Температурные зависимости относительного изменения сдвига (далее - сдвиг частоты) компонент Мандельштама-Бриллюэна для трех белковых растворов с различной концентрацией 100,50 и $5 \mathrm{mg} / \mathrm{ml}$ изображены на рис. 3. Детальное описание процедуры расчета относительного изменения сдвига частоты можно найти в работе [5]. Здесь укажем только, что приведенные на рис. 3 температурные зависимости „очищены“ от влияния буфера и представляют собой чистую динамику белка в растворе. Рассмотрим поведение температурной зависимости относительного изменения сдвига компоненты МБР для $100 \mathrm{mg} / \mathrm{ml}$ (рис. 3, a). Хорошо видно, что до $330 \mathrm{~K}$ относительный сдвиг компонент МБР в растворе БСА с концентрацией $100 \mathrm{mg} / \mathrm{ml}$ демонстрирует

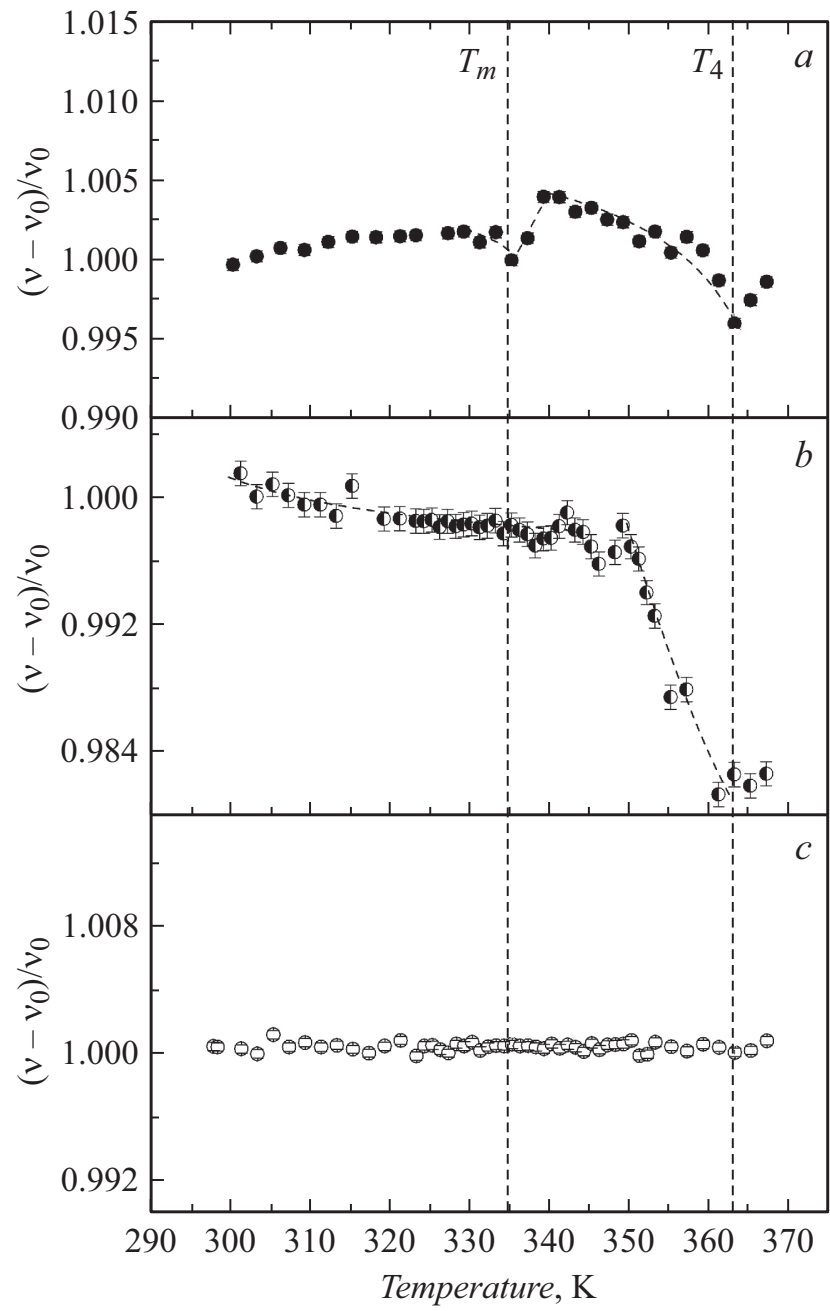

Рис. 3. Температурные зависимости изменения относительного сдвига дублета Мандельштама-Бриллюэна для белковых растворов с различной концентрацией: $a-100, b-50$ и $c-5 \mathrm{mg} / \mathrm{ml}$. Штриховые линии проведены на глаз. 
слабую зависимость от температуры. Начиная с $330 \mathrm{~K}$, наблюдается падение значений относительного сдвига компонент МБР. В окрестности $T_{m}=335 \mathrm{~K}$ наблюдается аномалия в виде ступеньки. Дальнейший нагрев ведет к немонотонному падению относительного сдвига компонент МБР. В окрестности второй температурной аномалии при $T_{4}=363 \mathrm{~K}$ зависимость меняется критическим образом. В работе [5] было показано, что аномалия в температурной зависимости сдвига частоты в окрестности $T_{m}$ связана с денатурацией белка и раскрытием II домена. Критическое поведение сдвига частоты при $T>350 \mathrm{~K}$ обусловлено переходом в гелеобразную фазу. Уменьшение концентрации белка в растворе до $50 \mathrm{mg} / \mathrm{ml}$ приводит к изменению температурных зависимостей сдвига частоты. До $330 \mathrm{~K}$ температурные зависимости для обеих рассматриваемых концентраций подобны (рис. 3, $a$ и $b$ ). При увеличении температуры мы можем видеть на рис. $3, b$ слабую аномалию в виде минимума сдвига частоты в окрестности $335 \mathrm{~K}$, связанную с денатурацией БСА. Еще одна аномалия, отсутствующая в температурной зависимости сдвига частоты в растворе БСА с концентрацией $100 \mathrm{mg} / \mathrm{ml}$, наблюдается в окрестности $345 \mathrm{~K}$ (ср. рис. $3, a$ и $b$ ). По-видимому, таким образом проявляются изменения в третичной структуре белка, связанные с раскрытием домена I. Отсутствие подобного максимума в температурной зависимости относительного изменения сдвига может быть связанно с тем, что при высоких концентрациях, таких как $100 \mathrm{mg} / \mathrm{ml}$, процессы агрегации и гелеобразования доминируют над процессами, связанными с раскрытием доменов, из-за увеличения вклада межмолекулярных взаимодействий. Дальнейшее увеличение температуры приводит к критическому поведению сдвига частоты (его уменьшению) и резкому изменению вида зависимости в окрестности $T_{4}=363 \mathrm{~K}$, что соответствует переходу в гелеподобную фазу. В растворе с концентрацией БСА $5 \mathrm{mg} / \mathrm{ml}$ поведение сдвига частоты не зависит от температуры (рис. 3,c), что, по-видимому, связано с малой чувствительностью используемой нами установки при таких концентрациях.

\section{2. Температурное поведение интенсивности дублетов мандельштам-бриллюэновского рассеяния света в растворах БСА с различной концентрации}

Рассмотрим поведение интенсивностей компонент дублета МБР при изменении температуры (рис. 4). Для белкового раствора с концентрацией $100 \mathrm{mg} / \mathrm{ml}$ интенсивность слабо возрастает до $330 \mathrm{~K}$, при дальнейшем нагреве испытывает немонотонное уменьшение со сменой режимов в окрестности температур 340 и $350 \mathrm{~K}$ (рис. 4, $a$ ). Подобное поведение интенсивности дублета МБР наблюдалось и при исследовании температурной денатурации лизоцима [6]. В обоих случаях уменьшение интенсивности связано с процессом

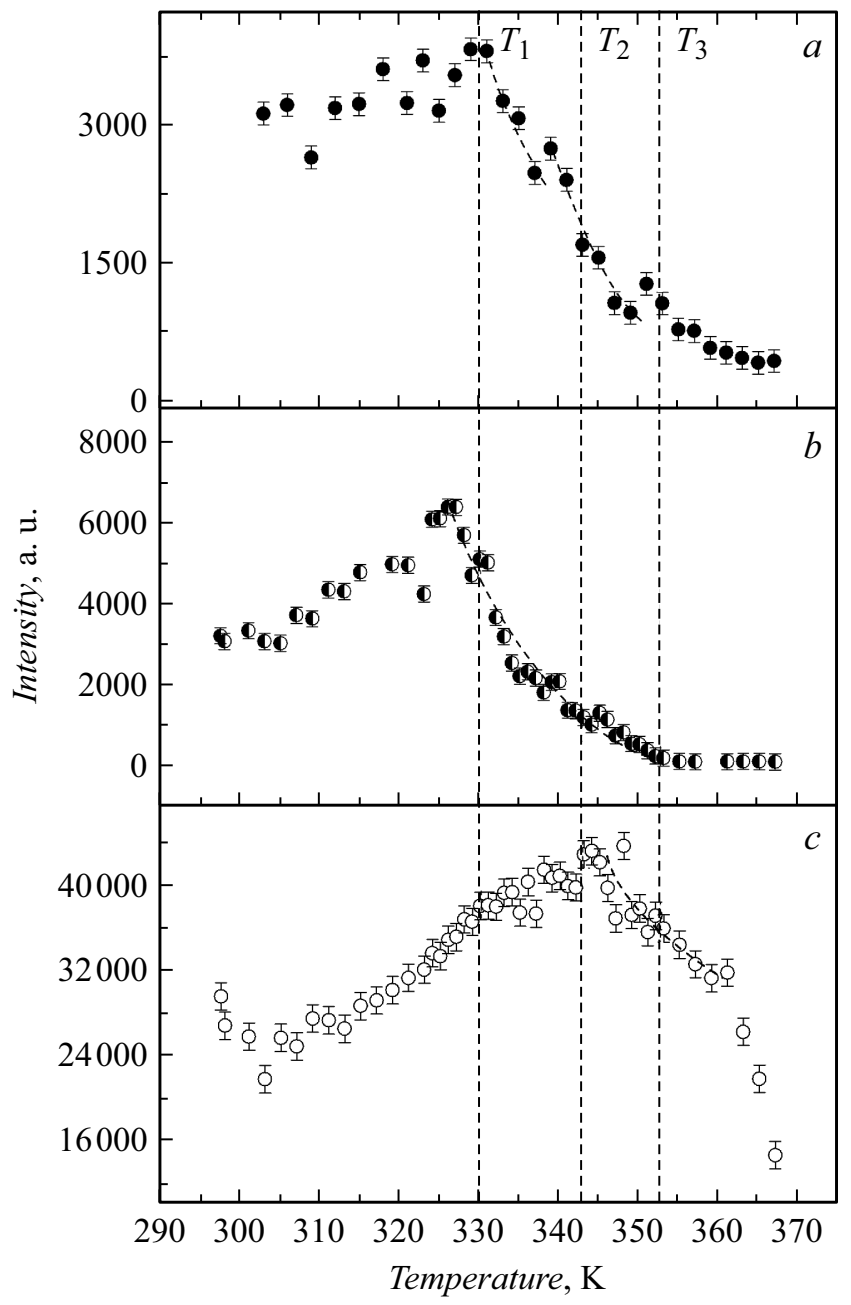

Рис. 4. Температурные зависимости изменения интенсивности компонент дублета мандельштам-бриллюэновского рассеяния света для растворов БСА с различной концентрацией: $a-100$, $b-50$ и $c-5 \mathrm{mg} / \mathrm{ml}$. Штриховая линия на рис. $4, a$ проведена на глаз.

агрегации и переходом системы в гель-фазу. В случае раствора БСА с концентрацией $100 \mathrm{mg} / \mathrm{ml}$ смена режима уменьшения интенсивности дублета МБР связана с многостадийностью процесса денатурации БСА, включающего в себя раскрытие различных доменов и образование фибрилл. Интенсивность компоненты МБР для белкового раствора с концентрацией $50 \mathrm{mg} / \mathrm{ml}$ ведет себя аналогично: возрастает до $325 \mathrm{~K}$ и при дальнейшем повышении температуры резко уменьшается практически до нулевых значений. Сдвиг области денатурации в область низких температур при уменьшении концентрации согласуется с результатами калориметрических измерений [13]. Температурное поведения интенсивности дублета МБР при $T>325 \mathrm{~K}$ - немонотонное: излом в температурной зависимости наблюдается в окрестности $343 \mathrm{~K}$, что согласуется с аномалией поведения сдвига частоты и связано с изменениями в третичной структуре белка (раскрытием I домена). При $T>355 \mathrm{~K}$ 
интенсивность компонент дублета стремится к нулю, а полуширина его увеличивается. Перейдем к случаю $5 \mathrm{mg} / \mathrm{ml}$. Интенсивность компоненты МБР такого белкового раствора в отличие от случая 50 и $100 \mathrm{mg} / \mathrm{ml}$ возрастает вплоть до $345 \mathrm{~K}$ - температуры начала раскрытия домена I. Дальнейший нагрев раствора, как и в случае других концентраций, приводит к падению интенсивности компоненты дублета МБР с изменением поведения температурной зависимости в окрестности $360 \mathrm{~K}$. Эту аномалию в температурной зависимости интенсивности можно связать с образованием геля. Но в случае раствора БСА с концентрацией $5 \mathrm{mg} / \mathrm{ml}$ свойства геля разительно отличаются от случаев 50 и $100 \mathrm{mg} / \mathrm{ml}$. Действительно, при концентрации $5 \mathrm{mg} / \mathrm{ml}$ раствор БСА в области высоких температур практически не мутнеет. В случае же 50 и $100 \mathrm{mg} / \mathrm{ml}$ в растворе БСА наблюдается критическая опалесценция при высоких температурах, гель мутнеет и становится практически непрозрачным.

\section{Выводы}

Уменьшение концентрации белка в растворе ослабляет вклад взаимодействий между молекулами белков. Подобное изменение внешних условий находит отражение в модификации температурного поведения сдвига частоты и интенсивности компонент дублета мандельштамбриллюэновского рассеяния света. Было показано, что при высоких концентрациях БСА в растворе процессы, связанные с раскрытием первого домена на второй ступени денатурации, в окрестности $343 \mathrm{~K}$ маскируются агрегацией белка. Уменьшение концентрации белка в растворе позволяет выделить более тонкие процессы, связанные с изменением структуры. Таким образом, варьируя концентрацию белка в буфере, мы можем анализировать вклад межмолекулярных взаимодействий в низкочастотную динамику белков и исследовать динамические процессы, связанные с раскрытием доменов и изменением третичной структуры белков.

\section{Конфликт интересов}

Авторы заявляют, что у них нет конфликта интересов.

\section{Список литературы}

[1] Frost B., Diamond M. // Nature Rev. Neuroscience. 2010. Vol. 11. P. 155.

[2] Galiskan G., Kisliuk A., Tsai A.M., Soles C.L., Sokolov A.P. // J. Chem. Phys. 2003. Vol. 118. N 9. P. 4230-4236.

[3] Perticaroli S., Nickels J.D., Ehlers G., Sokolov A.P. // Biophys. J. 2014. Vol. 106. P. 2667-2674.

[4] Lushnikov S.G., Dmitriev A.V., Fedoseev A.I., Zakharov G.A., Zhuravlev A.V., Medvedeva A.V., Schegolev B.F., SavvateevaPopova E.V. // JETP Lett. 2013. Vol. 98. N 11. P. 830-836.

[5] Dmitriev A.V., Vashchenkov V.E., Fedoseev A.I., Lushnikov S.G. //J. Raman Spectr. 2019. Vol. 50. N 4. P. 537.
[6] Svanidze A.V., Lushnikov S.G., Kojima S. // JETP Lett. 2009. Vol. 90. N 1. P. 80-84.

[7] Vashchenkov V.E., Fedoseev A.I., Petukhov M.G., Khavinson V.Kh., Savvateeva-Popova E.V., Lushnikov S.G. // J. Phys.: Conf. Series. 2014. Vol. 572. P. 012015.

[8] Henning M., Roosen-Runge F., Zhang F., Zorn S., Skoda M.W.A., Jacobs R.M.J., Seydel T., Schreiber F. // Soft Matter. 2012. Vol. 8. P. 1628-1633.

[9] Flora K., Brennan J.D., Baker G.A., Doody M.A., Bright F.V. // Biophys. J. 1998. Vol. 75. N 2. P. 1084-1096.

[10] Chodankar S., Aswal V.K., Kohlbrecher J., Vavrin R., Wagh A.G. // Phys. Rev. E. 2009. Vol. 79. N 2. P. 021912.

[11] Onuchic J.N., Luthey-Schulten Z., Wolynes P.G. // Annu. Rev. Phys. Chem. 1997. Vol. 48. P. 545-600.

[12] Fabelinskii I.L. Molecular scattering of light. NY.: Plenum Press, 1968.

[13] Deep S., Ahluwalia J.C. // Phys. Chem. Chem. Phys. 2001. Vol. 3. P. 4583-4591. 